\title{
Economic research and education in the era of digital economy
}

\author{
Mariya Kivarina ${ }^{1, *}$, and Anna Makarevich $^{1}$ \\ ${ }^{1}$ Yaroslav-the-Wise Novgorod State University, 41 Bolshaya Sankt-Peterburgskaya, Veliky \\ Novgorod, 173003, Russia
}

\begin{abstract}
At present, considerable attention is paid to the problems of understanding the most important trends in the formation and development of a digital economy, as well as the development of adaptive models of the modern education system, which reflects the relevance of the subject matter under study. The purpose of the article is to investigate the features of the transformation of economic science and education in the conditions of digitalization of the economy, to identify the main problems of the modern scientific and educational system and to identify the main ways to solve them. The research is based on an interdisciplinary approach using methods of logical-structural, situational and comparative analysis. Prospective directions of development of an economic science in conditions of digitalization are considered in the article, the problems which face the system of economic education at a stage of formation of a digital society are revealed. The significant influence on the transformation in the sphere of employment of the speed of the formation of educational networks for the training of personnel possessing the skills of teamwork for the effective resolution of technological, demographic and socioeconomic problems is proved.
\end{abstract}

\section{Introduction}

At the present stage of the development of society and the formation of new social relations, mankind has entered a next phase of its development, which is usually called the era of digitalization. During this period, human activity is directly related to the creation, processing and use of intangible resources, among which the most important place is occupied by intellectual capital and information presented in digital form. At present, a significant part of the employed population leaves the sphere of production of traditional types of goods and services and begins to actively participate in the processes of accumulation, storage, retrieval, processing, transfer and redistribution of information, which becomes a full-fledged product of public consumption.

Under the circumstances, the digital economy begins to take an active position in all spheres of public life, having a significant impact on the labor market. Digitalization of the economic system is the main direction of development of the state, economy and public relations, and the digital economy becomes a breakthrough technology in the system of

* Corresponding author: mariya.kivarina@novsu.ru 
sustainable development of society. An important condition for the effective development of the main spheres of human activity in the digital economy is the formation of an appropriate institutional environment. Personnel, education and science are included in the program "Digital Economy of the Russian Federation" to one of the key institutions within which conditions are created for the development of the digital economy.

The purpose of the article is to investigate the features of the transformation of economic science in the conditions of digitalization of the economy, to identify the main problems of the modern Russian system of economic education and to identify the main ways to solve them.

To achieve this goal, the following problems are solved in the article: 1) the concept and key factors of production in the digital economy are investigated, the special place among which is the human potential; 2) analyze the changes in the labor market in the era of the digital economy; 3 ) identify the problems of the formation of the scientific and educational environment in the digital economy and propose ways to overcome them.

The study is based on an interdisciplinary approach using the methods of logicalstructural, situational and comparative analysis. The findings and recommendations can become a basis for the further development of economic science and the improvement of the education system in today's digitalization of the economy.

\section{Literature review}

In recent years, there have been numerous predictions about the possible decline in employment due to the Fourth Industrial Revolution, associated with the development of such new technologies as robotics, digitalization, the creation of artificial intelligence, etc. Such forecasts are made by politicians, publicists, sociologists, futurists, engineers and other researchers. Despite the fact that most economists do not share these views, there are still researchers among them who negatively characterize the near future of the labor market. For example, some say that as a result of the introduction of new technologies, a large number of people of working age will remain undeserved in the market - in the rivalry between machines and people cars will finally win [1]. Others note that the world community is entering an era of high technological unemployment, whose victims the traditional welfare state cannot help [2]. Many agree that in the coming decades, about half of all existing professions will pass into the past $[3,4]$. Researchers predict such a high rate of technological change that workers simply cannot physically be retrained to new occupations, resulting in a steady increase in the number of unemployed [5]. Today's schoolchildren and students need to be prepared for the complete disappearance of a multitude of not only small- or medium-, but also highly-skilled jobs, as new technologies will increasingly assume the performance of intellectual functions that have until now remained the exclusive property of man [6]. The main existential problem that humanity will soon face is how to occupy ourselves in conditions of forced inactivity, when the very notion of "work" will go away, and smart cars will do everything for us [7].

Under the circumstances, economic science and education cannot develop according to the traditional scenario, their transformation is inevitable taking into account the existing realities. Classical economic theory is gradually transformed into an information economy, which is a collection of ideas and texts. This direction was not formed instantly and has its own history. Many prominent scientists were at the forefront of the information economy, among which Marshak, J. Stigler, J. Stiglitz, J. Ackerlof and other researchers were particularly notable. It is their work that can be considered the beginning of the process of formation of a new economic paradigm. The modern digital economy is not just the development of information technology; it is the emergence of radically new business models, the effectiveness of which is enhanced by the optimization and elimination of 
intermediaries. Business is becoming more dynamic and complex; it does not have a single right answer to how to organize its activities today. Companies developing new technologies and using various innovations, change business rules and destroy any barriers. Digital technologies, such as the IoT, big data, the use of mobile devices and devices, transform the ways of social interaction, economic relations and institutions. There are new forms of cooperation and coordination of economic agents for the joint solution of urgent problems.

\section{Methods of research}

The author's approach is based on the thesis that the development of the digital economy is a certain systemic transformation, in which two interrelated components can be distinguished:

a) scientific and educational - responsible for the effectiveness of ways, forms and mechanisms for applying economic knowledge in practice;

b) technical and technological - determined by the set and combination of material and non-material factors of production, that is, a set of technologies and equipment.

In this case, according to the authors, the first component creates the prerequisites for the formation of the second and lies at its basis. Hence it is advisable to consider the formation of a new type of economy, primarily through the transformation of the scientific and educational component of economic activity.

\section{Results and discussion}

Modern science and education, like everything in today's world, are developing with a high degree of uncertainty. The processes of adaptation of scientific and educational systems to the realities of the new economy are complicated by the fact that science and education are traditional, rather slowly developing institutions. However, despite the presence of certain conservatism, scientific and educational institutions are beginning to use more and more modern technologies for information transfer, provision of practice and communication at a distance. For example, at present higher education performs not only basic functions of information and education. Today, universities are institutions where, in addition to staging fundamental thinking, learn the most important social skills - tolerance, the rules of the game, decision-making and life situations. The formation of curricula and the construction of models of scientific and educational structures make it even more difficult to realize that it is currently impossible to clearly identify what knowledge and skills will be in demand even in the near future. Nevertheless, science and education must change; at least until in the modern post-industrial society the most important role is played by human potential and social capital.

In the last few years, Russia had sold a lot of public initiatives aimed at the development of education, the revival of the socio-professional activity, innovation and increasing prestige of science, including economic. Adopted in 2016 regulatory documents and public discussion of existing problems ensured a high involvement of different groups of citizens, business, the education community in decision-making in the field of education and science. An important event was the establishment in accordance with the decree of the President of Russia Vladimir Putin from December 11, 2015 No. 617 of the Russian public organization "the Society "Knowledge" of Russia", the first Congress of which was held on June 6-7, 2016.

An independent assessment of the quality of education since 2015 has become in fact an obligatory procedure for educational institutions. This assessment can make a huge 
contribution to the development of openness of education, but its mechanisms are still imperfect. To carry out such an assessment, special criteria and methodological bases have been developed, in the constituent entities of the Russian Federation, centers for assessing the quality of education are actively functioning and developing, and the Federal Institute for the Assessment of the Quality of Education operates. However, in normative legal acts there is not even a mention of the mechanisms for implementing this assessment, there is no indication of the subjects to be responsible for ensuring such mechanisms.

The situation at the regional level in many respects repeats the federal one. For example, on official websites of regional executive bodies, only 69 subjects of the Federation have specialized sections on the independent evaluation of the quality of education. And it's mainly about ratings. They are used in almost $75 \%$ of cases. About $39 \%$ of the constituent entities of the Russian Federation publish the results of the independent evaluation in the form of generalized analytics [8]. Often the reports are presented without detailed information on individual educational organizations. Meanwhile, ratings without explaining from which specific estimates the result was formed, do not give grounds for either making sound managerial decisions, or for choosing the place or program of instruction for children and their parents. Only in some regions is detailed information on educational services in the form of rankings (navigators), databases or infographics publicly available. In the beginning of 2016, about one third of all subjects of the Russian Federation began to use such formats.

Schools, higher and professional educational institutions are forced to work in the face of society's growing distrust of education in general [9]. This in many respects leads to an increase in control and supervision of educational organizations, increasing the burden on pedagogical workers. Surveys show that excessive reporting is the second most important negative factor after a low pay that makes the teaching job unattractive. This prevents the attraction of talented teachers to educational institutions and reduces their satisfaction with their work. For the development of education, a real autonomy of an educational institution is needed, which is provided by legal mechanisms, which now is practically not realized.

Nevertheless, over the past year, the Russian scientific community has conducted many important studies that yielded concrete results. Among them:

- preparing a document on the prospects for the development of the country's economy until 2025, which is presented in the form of a panorama of the development of strategic projects and programs, which makes it possible to clearly define the specialization of the major macro regions of Russia;

- development of methods for strategic management of the agro-food complex;

- proposal of the concept of the development of the budgetary system of the Russian Federation, corresponding to the goals of the socioeconomic development of the state.

The infrastructure of Russian science is improving, the material and technical support of research, and the availability of modern equipment. There is an increase in the citation of domestic publications. If in 2000-2004 the share of citations was 39.6, in 2010-2014 it increased to $54.05 \%$. Among the BRICS countries in publishing activity, Russia leads in physics, chemistry, and earth sciences. The number of Russian universities, celebrated in world rankings, has grown. So, in the rating of the World University Rankings 2016-2017 among the best universities in the world are already 24 Russian universities. In addition to the obvious leaders - Moscow State University. Lomonosov's Moscow State University, the Moscow Institute of Physics and Technology (State University), the St. Petersburg National Research University of Information Technologies, Mechanics and Optics - for example, universities such as the Higher School of Economics, Kazan Federal University and Tomsk State University.

Research funds play an important role in the development of research. In 2016, the Russian Foundation for Basic Research joined the Russian Humanitarian Scientific 
Foundation. It is expected that the merger will optimize the management of funds, under their jurisdiction, as well as to organize a unified procedure of access to grants, regardless of the scientific profile of the project. At the same time, it is important that, within the framework of the RFBR grant policy, the necessary attention be paid to supporting projects aimed at the practical implementation of research results.

In spite of this, in 2016 the scientific community expressed great anxiety in connection with the continuing negative phenomena in science. The May decrees of the President of the Russian Federation are not implemented. Thus, the share of research and development costs should have been $1.77 \%$ of GDP. However, in reality it was $1.1 \%$. This is 2.5 times lower than in the US, 3.5 times lower than in the Republic of Korea, 2-2.5 times lower than in France and Germany. A similar share of spending on science is observed in countries such as Brazil, Malaysia and Turkey.

Another reason for concern is the bias in funding research, when the budget for applied research far exceeds the costs of fundamental research. The current model of organization of science does not fully correspond to the task of transition to innovative development of the country and does not give it a chance to overcome the crisis and take the leading position in the world.

For the further development of economic science and education, it is necessary to carry out in the near future a number of primary measures, such as:

- development of the National Innovative Development Program, which should ensure a full innovation cycle - from basic research to implementation. This document will contribute to the growth of demand for innovation - the main condition for the activation of innovation and economic growth;

- legislative consolidation of the right of the Russian Academy of Sciences for scientific and methodological guidance of all scientific organizations located on the territory of Russia, coordination of candidacies of heads of major scientific and educational institutions, expert evaluation of the most important state decisions and legislative acts;

- division of the competence sphere of the Russian Academy of Sciences and the Federal Agency of Scientific Organizations;

- strengthening of higher education programs in engineering and technical specialties.

In recent years, there has been an increase in the state's interest in supporting so-called bottom-up innovations. In this model, state funds support the most competitive and promising projects of young scientists and small high-tech companies within the priority areas of the country's development. This allows creating an open environment for private initiatives, creating more high-tech companies. It is particularly important to support an open innovation environment in education itself.

For civil society institutions, business community and educational organizations, the task of forming a system for supporting knowledge-intensive projects becomes urgent. In this regard, it is important to note the activities of the Foundation for Promoting the Development of Small Forms of Enterprises in the Scientific and Technical Sphere (Fund for Promoting Innovation). During the existence of the Foundation, 60 thousand applications were submitted, more than 15 thousand innovative projects of young scientists were supported, over 5 thousand start-ups were created, 14 thousand contracts for research and development work were concluded, and a network of 70 regional representatives was formed.

Recently in the conditions of digital public relations the leading role in the pedagogical process belongs to electronic educational technologies. One of the most demanded pedagogical trends is the formation of mass open online courses (massive open online courses - MOOC) for level and supplementary education systems.

The Order of the Ministry of Education and Science of the Russian Federation of August 23, 2017 №816 approved the procedure for the use of educational organizations e- 
learning and distance education programs. According to this document, organizations that carry out educational activities have the right to implement educational programs or their parts with the use of e-learning, distance learning technologies, organizing training sessions in the form of online courses, and students who have mastered educational programs in the form of online courses are provided with the appropriate document, and gives the right to admit the student to intermediate certification in another educational organization.

Online education has two main functions. The first is to support traditional learning with a mixed model. The second is to provide those students who do not have access or resources to attend the university, a quality and concentrated learning process. And for universities, it is important to ensure that the online version of their courses coincides with the experience that students receive full-time education.

One of the innovative projects in education is mass open online courses, which allow solving a number of problems facing the modern education. Open educational resources help in digital pedagogy to provide mass education (the number of registered at different courses reaches hundreds of thousands of people), accessibility to every student in any territorial point of the world and high quality of education, as these courses were created by the best Russian and foreign teachers. These modern digital technologies allow integrating Russian education into the world educational environment and forming people of new professions for digital organizations. One of the priority directions in the trajectory of digital pedagogy is the formation of a digital educational environment in which mass open online courses will be successfully implemented. This promising form of distance education gives the freedom of learning; it gives an opportunity to independently choose their future profession, increases the motivation of learners to acquire skills that allow them to be competitive in the digital space. MOOC removes space-time constraints in the study of the educational course or its parts go beyond one educational organization.

Now on the market of electronic educational services the largest platforms of mass open online courses have been formed and have united a number of large world universities, including Coursera, KHAN, edX, Udacity and others. This shows that the informational educational environment is accessible, and learning and cognition becomes a process. In its structure, mass open online courses include video lectures (video-fragments), training exercises (assignments for fixing the material), homework, control tasks [10].

In the period of digital transformation, the role of the university teacher changes significantly, they must use all possible methods, methods, means of electronic and distance learning, and also participate in innovative transformations of society and business communities, then they will be in demand in the information educational space. Teachers the authors of online courses organize and involve learners in networked group learning, forming their creativity, because the creative class is able to manage the processes of sustainable social and economic development in conditions of digital transformations of social relations.

In the contemporary debate on vocational education, an important transition to a new terminology has been implemented, reflecting significant progress in its content. It is rather not about mastering knowledge, but acquiring skills-skills, and moreover, acquiring not individual skills, but groups of skills or competencies. A new paradigm of terms arose: hard skills, soft skills, digital skills, which reflect cardinal changes in the educational sphere. For all professions there will be a different ratio of the above skill groups [11].

The first group of skills, as a rule, includes professional skills, which can be brought to automatism and which can be assessed, for example, with the help of an examination. The latter belong to the category of personal qualities, are acquired in the process of socialization of a person and mastering of professional experience, allow a person to be successful regardless of the specifics of his main activity. As for the third - it is important here who should receive a "package" of such skills. For example, for "non-digital" 
professions (doctor, lawyer, actor, teacher of literature), digital skills is a standard package of competencies that they need as ordinary members of a modern digital network society. Those who constitute the technical elite of this society need a completely different package: for members of this group, digital skills acquire the importance of hard skills. The same goes for soft skills. For parts of specialists communication and management skills are necessary to maintain a common professional level, and, for example, for the elite of the pedagogical and management communities, such competencies, along with narrow professional knowledge, are included in the hard skills package. After all, it is known that talented teachers differ from average teachers not so much by the depth of their knowledge as by the ability to communicate them, i.e. by a more perfect form of communication.

In modern discussions, the ratio of the data of the three components and the ways of their harmonious arrangement are actively discussed. The correct answer to this question can only be the strengthening of the fundamental nature of education for the preparation of a student, capable of continuously developing in the future, competent both in technical and human sciences, possessing various interdisciplinary knowledge and transdisciplinary research methods [12]. The proportions of various competences are determined by many factors - from the choice of the future profession and the demands of social development to the cultural specificity of the region where the person lives.

In business models there is a constant "breaking" of the skill set, and, with a minimum time lag, followed by a high demand for new skills, which determines the requirements for new professions. That is, in all industries, in all areas, the "shelf life" of skill sets has dramatically decreased. With the development of robotics, many necessary skills will simply disappear. Moreover, even in industries with minor technological changes, changes in the demographic situation or targeting other markets will change the necessary skills.

When examining the question of what specific skills are necessary for modern industries, it is important to consider the time process of the impact of information technology on various industries that affect the business model and determine the relevance of skills of the workforce (Fig. 1).

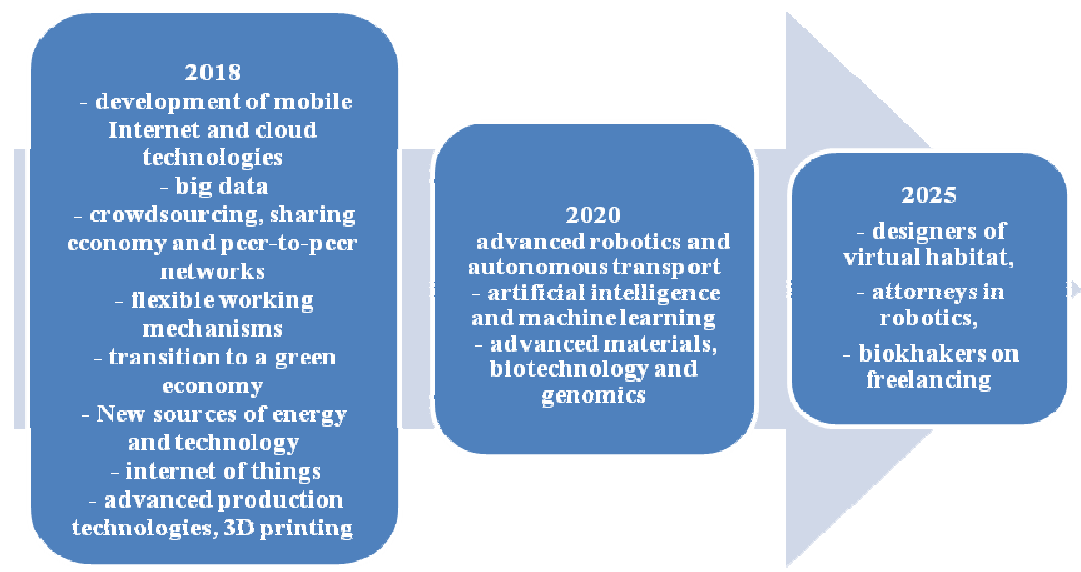

Fig. 1. Time process of the impact of information technology on various industries.

The combination of skills required for the wider use of digital technologies can be grouped in three directions:

a) skills in the field of information and communication technologies (ICT) for programming, application development and network management; General ICT skills for professional purposes;

b) additional ICT skills for performing new tasks related to the use of ICT in work, for example: information processing, self-management, problem solving and communication; 
c) digital literacy skills, as well as social and emotional skills that are critical to ensuring the effective use of digital technologies by all people in everyday life.

The question of which levels of training, retraining and advanced training it is necessary to improve certain skills also becomes topical. You can identify the following forms of training and levels of digital training, indicating the desired competencies and skills in a particular area of ICT (Table 1).

Table 1. Formation of digital competencies in various forms of training.

\begin{tabular}{|c|c|c|}
\hline $\begin{array}{l}\text { Level of } \\
\text { education }\end{array}$ & $\begin{array}{l}\text { Level of } \\
\text { digital } \\
\text { training }\end{array}$ & Skills of information and communication technologies \\
\hline $\begin{array}{l}\text { Fellowship } \\
\text { Doctoral } \\
\text { studies }\end{array}$ & analytical & $\begin{array}{c}\text { Searching for information, the ability to access it, analysing } \\
\text { and summarizing the information received, developing } \\
\text { theoretical concepts and practical recommendations for } \\
\text { applying the experience gained }\end{array}$ \\
\hline $\begin{array}{l}\text { MBA } \\
\text { Retraining } \\
\text { Master } \\
\text { (Technical } \\
\text { Specialists) }\end{array}$ & professional & $\begin{array}{l}\text { Skills required for the formation, functioning, maintenance } \\
\text { and development of information and communication systems } \\
\text { (skills in working with modern software products, operation, } \\
\text { maintenance, management, design of information } \\
\text { architecture, design, research and development in the field of } \\
\text { ICT) }\end{array}$ \\
\hline $\begin{array}{c}\text { Training } \\
\text { Master (non- } \\
\text { technical } \\
\text { specialists) } \\
\end{array}$ & advanced & $\begin{array}{l}\text { Ability to navigate in developing digital conditions, including } \\
\text { new software, analytical technologies and reporting } \\
\text { platforms. Ability to apply digital technology. Knowledge } \\
\text { and skills in the field of ethics of ICT application. }\end{array}$ \\
\hline $\begin{array}{l}\text { Bachelor's } \\
\text { program } \\
\text { Vocational } \\
\text { education } \\
\text { Secondary } \\
\text { education }\end{array}$ & basic & $\begin{array}{l}\text { Components of digital literacy - access to the network, basic } \\
\text { programming and algorithmization skills, product creation } \\
\text { and communication information exchange in individual or } \\
\text { team work, possession of computer technologies, ability to } \\
\text { use the web environment. Interpretation and representation of } \\
\text { information using ICT tools. }\end{array}$ \\
\hline Population & elementary & $\begin{array}{l}\text { Computer literacy. } \\
\text { User skills: the primary skills needed to obtain services in the } \\
\text { digital environment. }\end{array}$ \\
\hline
\end{tabular}

The systematic nature of the training of specialists requires the consideration of the most progressive phenomena that are at the forefront of technological development, the trends in the development of world scientific and technological progress and the world economy that are "instructed" not to teach what is today but to what will be in the near future. The sixth technological cycle, which humanity has entered into, is connected with the NBIC-convergence: consolidation and synergetic strengthening of the achievements of nano-, bio-, information and cognitive technologies, which will result in the complete merger of these technologies into a unified scientific and technological area of knowledge. This feature of this system must be taken into account in the system of economic education, which should be oriented towards the formation of research competencies and teamwork skills.

The sixth technological cycle will require overcoming the narrowly specialized nature of the organization of science and education. In this regard, the issue of interdisciplinary training of personnel is of particular urgency. In the face of information technology, for the first time, technology has emerged that is of a branch nature. Information technology has become a link that unites all science and technology [13]. In connection with this, the question of preparing supra-disciplinary specialists is actualized, which, however, does not mean the abolition of a highly specialized system of training personnel. The creation of 
nature-friendly technologies of a new way is connected with convergence, the synthesis of humanitarian and natural science knowledge.

Thus, economic science evolves from narrow specialization to interdisciplinarity, then superdisciplinarity and transdisciplinarity, synergetic effect, interpenetration and interaction with other sciences. Obviously, in accordance with this logic, the transformation of existing educational approaches and methods is inevitable, namely, the creation and development of a methodology related to the fundamental processes of convergence of knowledge that are currently absent in the educational process.

In the digital age, a number of difficulties arise in all sectors of the country's economy, related to the transformation of state mechanisms into cyberspace for the management of socio-economic systems. Before the Russian system of economic education at the stage of forming a digital society there are a number of problems, the main ones of which are:

1. The transfer of knowledge, the formation of skills and skills to master is carried out using digital and information technology, which is associated with the need to use all the possibilities of electronic, distance and interactive learning.

2. The world economic space sets the demand for new types of competencies. According to the latest research, the following competencies will be the most popular in the world and national practice in the near future $[14,15]$ :

- Existential competencies related to concentration and attention management;

- Empathy and emotional intelligence;

- Cooperation (a skill that must be built into different aspects of work and learning);

- Thinking: critical, problem-oriented, systemic, cooperative-creative;

- Creativity;

- Work in interdisciplinary environments and knowledge of the emerging "general language of concepts" (including system engineering and economics);

- Literacy of the 21 st century: understanding global problems, managing your health, understanding the principles of society, taking care of the environment, financial literacy and so on.

- Skills in ICT and media technologies, including programming and information hygiene;

- Flexibility and adaptability;

- Ability to learn, unlearn and re-learn during life;

- Responsibility in the work (including ethics of interaction with other members of the society and working ethics of human-centered services).

The above-mentioned competences of the future determine the formation of a modern man as a "man of a new formation", who will have the ability in his work to use research and design methods. People of the creative class can be competitive in the information space.

3. The shift of value orientations in the consumption society forms in the educational system a new type of trainee.

Currently, economic education is undergoing a digital transformation, goes beyond the time frame of life, beyond the educational institutions using the unique capabilities of network and digital technologies, involving all direct and indirect participants in the educational process. The role of the teacher changes, new ways of its interaction with learners arise, new approaches and methods of teaching are formed, which ultimately leads to the inevitability of the formation of a new system of economic education capable of educating a holistic, multifaceted and multifunctional specialist. 


\section{Conclusion}

In the modern world there are radical transformations that affect all spheres of life. Digitalization fundamentally changes the ways in which education is received, but many problems still remain: the inequality of access to digital technologies, the undermining of the quality of education due to various reasons, its mercantilization. The more attention must be paid to ensuring that modern information and communication technologies can be used to improve the quality and effectiveness of education, and to promote equality of educational opportunities. Without this, it is impossible to realize the ambitious goals set by Russian society. In conditions when a person becomes a key element of the digital economy, education acquires not only the importance of the public good and the fundamental human right, but the strategic priority of the development of the Russian society that solves the most complicated task of "launching the future" in the conditions of cardinal civilizational changes.

Based on the results of the study, the following conclusions can be drawn. First, the system of Russian education has a sufficiently high potential for training specialists in the digital economy. This is especially important, since in the digital economy the person will focus mainly on the realization of new opportunities and systemic organization of interaction in the ecosystem of people and machines, and routine operations will be performed by machines. Secondly, at present in our country there are original organizational and technological solutions for creating an effective infrastructure for the digital economy. Thirdly, the integration and development of specific cases based on modern principles of the digital economy will create a synergistic effect and lead to a general growth of the Russian economy.

\section{References}

1. B. Kramer, Technovation, 35, 71 (2015). Doi: 10.1016/j.technovation. 2014.10.005.

2. C.B. Frey, M.A. Osborne, Technological Forecasting and Social Change, 114, 254-280 (2017). Doi: 10.1016/j. techfore.2016.08.019.

3. F. Heyman, Economics Letters, 145, 246-251 (2016). Doi: 10.1016/j. econlet.2016.06.032.

4. T. Berger, C.B. Frey, Regional Science and Urban Economics, 57, 38-45 (2016). Doi: 10.1016/j.regsciurbeco.2015.11.003.

5. Y.J. Kim, K. Kim, S.K. Lee, Futures, 87, 1-9 (2017). Doi: 10.1016/j. futures.2017.01.003.

6. M.J. Sousa, M. Carmo, A.C. Gonçalves, R. Cruz, J.M. Martins, Journal of Business Research, 94, 227-240 (2019). Doi: 10.1016/j.jbusres.2018.02.005.

7. A. Carnevale, Robotics and Autonomous Systems, 86, 144-151 (2016). Doi: 10.1016/j.robot.2016.08.027.

8. T. Volosovets, I. Kirillov, A. Buyanov, Procedia - Social and Behavioral Sciences, 237, 1299-1303 (2017). DOI: 10.1016/j.sbspro.2017. 02.213.

9. C. Watanabe, K. Naveed, P. Neittaanmäki, Technology in Society, 48, 70-96 (2017). Doi: 10.1016/j.techsoc.2016.11.001.

10. M. Baygin, H. Yetis, M. Karakose, E. Akin, An effect analysis of industry 4.0 to higher education, ITHET, 1-4 (2016). Doi: 10.1109/ITHET.2016.7760744.

11. M.J. Sousa, A. Rocha, Journal of Business Research, 94, 257-263 (2019). Doi: 10.1016/j.jbusres.2017.12.051. 
12. G. Reischauer, Technological Forecasting and Social Change, 132, 26-33 (2018). Doi: 10.1016/j.techfore. 2018.02.012.

13. V.I. Syryamkin, E.G. Syryamkina, Procedia - Social and Behavioral Sciences, 166, 468-471 (2015). Doi: 10.1016/j.sbspro.2014.12.556.

14. P. Caligiuri, A. Mencin, B. Jayne, A. Traylor, Journal of World Business, 54 (1), 14-23 (2019). Doi: 10.1016/j.jwb.2018.09.002.

15. A.A. Gümüsay, T.M. Bohné, Research Policy 47, 363-378 (2018). Doi: 10.1016/j.respol.2017.11.008. 